\title{
POLÍTICA DE SAÚDE E EQÜIDADE
}

\author{
Ana Luiza d’ávila Viana \\ Márcia Cristina Rodrigues fausto \\ Luciana Dias de Lima
}

\begin{abstract}
Resumo: O artigo analisa a inclusão da questão da eqüidade na área da saúde, sobretudo nas políticas de saúde. Apresenta informações recentes quanto à alocação de recursos financeiros, oferta e utilização de serviços em saúde no Brasil, em um universo particular de municípios, e conclui que ocorreram alguns avanços positivos do ponto de vista da eqüidade, desde a implantação do SUS, notadamente quando do processo de descentralização da política de saúde.

Palavras-chave: política de saúde; eqüidade e oferta; utilização de serviços de saúde.
\end{abstract}

Abstract: This article analyses the issue of equity in the area of health, particularly with regard to health care policy. It presents recent information on the allocation of financial resources and the supply and utilization of health care services throughout a selected group of municipalities in Brazil, and concludes that progress has been made in terms of equity since the establishment of SUS, particularly as reflected in the decentralization of health care policy.

Key words: health care policy; equity and supply; equity and supply; utilization of heath care services.

A s reformas da política de saúde são conduzidas, não só no Brasil, mas em boa parte do mundo, para responder a duas questões centrais: como otimizar os escassos recursos destinados ao setor e como organizar um sistema de saúde eficaz e com envergadura suficiente para atender às necessidades de saúde da população.

Em fins dos anos 70 e início dos 80, diversos países, inclusive o Brasil, questionavam as saídas para o setor público decorrentes de severa crise econômica que atingia as nações e que exigiam um redimensionamento do papel do Estado.

No Brasil, essas questões foram debatidas ao longo dos anos 80 e 90, e em relação à política de saúde, optou-se pela ampliação da participação democrática e da garantia dos direitos de cidadania, mediante conformação de um sistema de saúde com características universalizantes, de cunho igualitarista, sustentado pela idéia de justiça social.

A reforma implementada no sistema de saúde brasileiro no final dos anos 80 trouxe como questão de fundo não só a garantia do direito à saúde, mas, em essência, a noção de eqüidade quanto à distribuição mais ampla dos recursos da saúde. Essas duas questões buscavam dar res- postas às críticas dirigidas ao sistema de saúde vigente àquela época, cujo formato deixava à margem do sistema grande parte da população brasileira: os mais pobres, os que se encontravam em condições de desvantagem social e, por isso, os que talvez mais precisassem de atenção à saúde.

Assinale-se que as investigações em saúde demonstram que os piores índices de saúde encontram-se entre os grupos populacionais mais vulneráveis localizados na base da pirâmide social. Essas disparidades podem ser verificadas nas condições de vida e saúde entre diferentes grupos sociais e entre distintas áreas geográficas do mesmo país. Tradicionalmente, a epidemiologia ocupa-se dessa temática, e inúmeros estudos apontam para as desigualdades de adoecer e morrer na sociedade, assinalando as diferenças em relação ao lugar, tempo, idade e sexo, bem como entre grupos, etnias, gênero e classes sociais.

\section{DIMENSÕES DA DESIGUALDADE EM SAÚDE}

De acordo com Mackenbach e Kunst (1997), as desigualdades em saúde definem-se pela prevalência ou incidência dos problemas de saúde entre os indivíduos do mais alto e 
mais baixo status socioeconômico. Destacam, os autores, que as desigualdades interligam-se ao status socioeconômico do grupo ao qual pertencem os indivíduos.

As dimensões da desigualdade em saúde são atribuídas a diferentes determinantes que podem corresponder a um conjunto de fatores interligados às condições de saúde e adoecimento, que definem o padrão de morbimortalidade dos diferentes grupos sociais, e/ou as diferenças na distribuição, organização e utilização dos recursos em saúde.

A existência e a persistência das desigualdades no acesso e uso de serviços de saúde, mais recentemente, são um dos principais pontos de atenção dos policy makers, das investigações acadêmicas e dos próprios administradores dos serviços de saúde.

O tema desigualdades em saúde passou a ser tratado para além das diferenças entre os grupos, incorporando nas análises conceituais a dimensão da justiça social. Esse enfoque, além de caracterizar os diferentes tipos de desigualdade, remete a análise para o campo político, com incorporação de valores éticos e morais explícitos nas bases contratuais de determinada sociedade.

Nesse sentido, as desigualdades em saúde são percebidas e têm-se tornado objeto de atenção nos mais diferentes modelos de sistemas de saúde, nos países mais desenvolvidos e nos mais pobres e em regimes políticos e sociais variados. É bem verdade que o grau de desigualdade, seus determinantes e efeitos diferem entre as sociedades e internamente nos próprios países. O que se quer enfatizar, no entanto, é o caráter contemporâneo e universal desse debate e suas implicações na formulação e condução de políticas que podem ou não interferir nos diferenciais de desigualdades resultantes de processos sociais, políticos e econômicos.

O tema eqüidade passa a receber maior atenção na década de 80. Um dos marcos dessa discussão no campo da saúde é a estratégia formulada pela OMS - "Saúde Para Todos no Ano 2000", que visa a promoção de ações de saúde baseadas na noção de necessidade, destinadas a atingir a todos, independente de raça, gênero, condições sociais, entre outras diferenças que possam ser definidas socioeconômico e culturalmente.

Apesar de existir um problema terminológico na variedade conceitual de eqüidade e, em alguns casos, problemas também com o significado da expressão quando utilizado no sentido das desigualdades, percebe-se, de modo geral, que há consenso ou aceitação ampla na literatura da definição formulada por Whitehead (1991), ou seja, eqüidade em saúde, para a autora, remete à noção de que, de acordo com os ideais, todos os indivíduos de uma sociedade devem ter justa oportunidade para desenvolver seu pleno potencial de saúde e, no aspecto prático, ninguém deve estar em desvantagem para alcançá-lo. Conseqüentemente, eqüidade em saúde refere-se à redução das diferenças consideradas desnecessárias, evitáveis, além de serem consideradas injustas.

Partindo desse princípio, a questão central a ser tratada pelas políticas que almejam eqüidade em saúde, é a redução ou a eliminação das diferenças que advém de fatores considerados evitáveis e injustos, criando, desse modo, igual oportunidade em saúde e reduzindo as diferenças injustas tanto quanto possível.

Em que pese as diferenças conceituais e terminológicas, o ponto central da contribuição de Whitehead é o entendimento das desigualdades em saúde na perspectiva da justiça social. Assinale-se que o conceito apresentado pela autora implica uma discussão política e de juízo de valor, quando incorpora a idéia de justiça no processo de redução das desigualdades evitáveis e desnecessárias. Isso significa dizer que existe mobilidade no conceito de eqüidade, em que o entendimento que se tem sobre política equânime depende da sociedade à qual se aplica o conceito e do momento ou tempo em que se está pensando a questão. O que se considera injusto ou o que se pretende fazer para reduzir as disparidades sociais pode ter dimensões e valores diferentes para espaços sociais distintos em diferentes momentos.

A mesma autora distingue alguns critérios que classificam as desigualdades em saúde, diferenciando as injustas, das que não expressam injustiças, porque não dependem de intervenção ou não apresentam relação causal com as diferenças de classe. Entre os critérios mencionados pela autora, são destacados os que ela considera mais consensuais na literatura:

a) o que não define as desigualdades como injustas:

- variações biológicas naturais;

- comportamentos perigosos que são escolhas dos indivíduos;

- vantagens temporárias de um grupo, como saúde, as quais podem ser incorporadas rapidamente por outros grupos;

b) o que define as desigualdades como injustas:

- comportamentos perigosos nos quais os indivíduos têm pouca escolha em relação ao modo de vida;

- condições de vida definidas por fatores socioeconômicos; 
- condições de trabalho - exposição a fatores de risco;

- inadequado acesso aos serviços de saúde ou outros serviços públicos essenciais.

Starfield (2001:53), mais recentemente, discute o conceito indicado por Whitehead e propõe a seguinte definição, por ela considerada alternativa, para eqüidade em saúde: "Eqüidade em saúde é a ausência de diferenças sistemáticas em um ou mais aspectos do status de saúde nos grupos ou subgrupos populacionais definidos socialmente, demograficamente ou geograficamente. Eqüidade nos serviços de saúde implica em que não existam diferenças nos serviços onde as necessidades são iguais (eqüidade horizontal), ou que os serviços de saúde estejam onde estão presentes as maiores necessidades (eqüidade vertical)."

Em suma, para a autora, a eqüidade no cuidado à saúde define-se enquanto igualdade de acesso para iguais necessidades, uso igual dos serviços para necessidades iguais e igual qualidade de atenção para todos.

Nessa mesma linha, a International Society for Equity in Health (ISEqH), presidida por Barbara Starfield, tem apresentado uma definição de eqüidade numa linha técnico-operacional, que textualmente exclui do conceito a noção de desigualdades injustas e aborda as diferenças como sistemáticas e potencialmente remediáveis: "eqüidade é a ausência de diferenças sistemáticas e potencialmente remediáveis em um ou mais aspectos de saúde nos grupos ou subgrupos populacionais definidos socialmente, economicamente, demograficamente ou geograficamente" (Macinko; Starfield, 2001:1). Tradução dos autores.

Os debates e as definições conceituais mais recentes sobre desigualdades e eqüidade em saúde são essencialmente sustentados pela teoria da justiça formulada por dois importantes autores contemporâneos, Raws (2000) e Sen (2001), cujas análises têm influenciado o debate sobre o tema, ainda que justiça e eqüidade sejam abordadas com base em perspectivas diferentes, pois a idéia de justiça carrega um sentido distributivo, que implica na igualdade de oportunidades, tendo em vista as diferentes necessidades dos cidadãos.

O ganho obtido com a inclusão do debate da justiça social na conformação de políticas mais equânimes é imensurável, uma vez que pressupõe tratamento desigual para os que estão em condições de desvantagem, abrindo espaço para o que se considera como um tipo de "discriminação positiva”, e, conseqüentemente, assumindo os dilemas políticos inerentes ao enfrentamento das largas desigualdades verificadas entre os diferentes grupos populacionais.
Essas análises adquirem força no mundo contemporâneo porque as fragmentações e as diversidades de processos sociais verificados no mundo globalizado restringem o espaço das versões homogêneas de vida social. Dessa forma, a noção de igualdade só se completa se compartida à noção de eqüidade. Não basta um padrão universal se ele não comportar o direito à diferença. Não se trata mais de um padrão homogêneo, mas de um padrão equânime.

Essa é a essência do debate da eqüidade em saúde que é aplicado ao problema dos recursos limitados e a forma mais equânime de distribuí-los. A idéia de que a ausência de saúde pode afetar as oportunidades dos indivíduos de fazer ou ser algo, evidencia a importância da reflexão sobre a idéia de justiça social para o caso da saúde e, nesse sentido, é fundamental considerar as diferenças para aplicação de políticas e programas mais efetivos, que dêem respostas a problemas específicos e, conseqüentemente, atuem para redução das desigualdades injustas.

Ao longo dos anos 90, a Organização Mundial da Saúde, o Banco Mundial, o Banco Interamericano de Desenvolvimento, entre outros organismos internacionais, classificaram a eqüidade como eixo central do debate econômico e da reforma do Estado. Entretanto, o questionamento que circunscreve os rearranjos da relação Estado/Sociedade está longe de ser um consenso. Diferentes perspectivas e interesses estão presentes na arena política e temas como papel do Estado, descentralização, gasto público e distribuição dos recursos são apresentados em diferentes proposições.

A eqüidade tem recebido diferentes definições e ênfases nos estudos teóricos e empíricos concernentes ao acesso e uso dos serviços de saúde. Os enfoques conceituais destinam-se a análise do tema de forma global no campo da saúde, no acesso e nas barreiras para o acesso aos serviços de saúde (na atenção básica e demais níveis de atenção), na qualidade dos serviços, nos fatores determinantes das condições de vida e saúde e nos fatores de ordem política que podem promover ou dificultar a eqüidade.

Travassos (1997) considera importante distinguir eqüidade em saúde de eqüidade no uso ou consumo de serviços de saúde. Essa distinção, para a autora, é importante uma vez que os determinantes das desigualdades no adoecer e no morrer diferem dos das desigualdades no consumo de serviços de saúde.

As desigualdades em saúde refletem, dominantemente, as desigualdades sociais, e, em função da relativa efetividade das ações de saúde, a igualdade no uso de serviços é condição importante, porém não suficiente, para 
diminuir as desigualdades relativas a adoecer e morrer, existentes entre os grupos sociais.

A implementação de políticas equânimes, ou seja, que reconhecem as diferenças (justas ou injustas) atinentes às necessidades, implica, portanto, na definição de campos específicos de sua aplicação. Pode-se perceber, pelo menos, três importantes campos na saúde: distribuição de recursos; oportunidades de acesso e utilização dos serviços.

Embora se considere que a inclusão do princípio de eqüidade na formulação de políticas de saúde não garante, de imediato, a implementação de políticas que resultem em melhores níveis de eqüidade (na prestação de serviços), esse debate vem alcançando relevância no setor, promovendo importante redefinição nos rumos das políticas de saúde.

No primeiro momento, pode-se dizer que a inclusão da eqüidade ocorreu no plano da formulação das políticas e programas, na garantia do acesso universal aos serviços de saúde. Posteriormente, em sua fase de execução, a eqüidade passou a ser um dos princípios norteadores da política, seja no aspecto do acesso e utilização do sistema, seja na alocação dos recursos financeiros.

Com todas as limitações e as dificuldades verificadas no campo da saúde quanto à redução das desigualdades e da identificação dos determinantes específicos desse setor, é possível dizer que a eqüidade na alocação e no consumo de serviços de saúde é uma dimensão própria das políticas, uma vez que se trata de responsabilidade específica do sistema de saúde.

Nota-se como esses conceitos podem ser operacionalizados para o caso da política de saúde no país, que tem como elemento balizador o atual desenho da implementação do SUS.

\section{IMPACTOS QUANTO À EQÜIDADE NA ALOCAÇÃO DE RECURSOS FINANCEIROS, OFERTA E UTILIZAÇÃO DE SERVIÇOS}

Durante a década de 90, o Brasil vivenciou um processo de transferência gradativa de competências e recursos do nível federal para estados e, sobretudo, para os municípios. A descentralização da política de saúde foi marcada, nos últimos dez anos, pela edição de diversas Normas Operacionais pelo Ministério da Saúde - portarias ministeriais - que culminaram por se tornar os principais instrumentos de regulação nacional desse processo. ${ }^{2}$

As normas da descentralização foram alteradas e sucessivamente substituídas, apresentando diferenças impor- tantes entre si. De forma geral, pode-se afirmar que as últimas normas publicadas nos anos 90 definem:

- as diferentes atribuições gestoras do nível federal, estadual e municipal sobre o planejamento e a programação da assistência à saúde, pagamento, execução, controle, avaliação e auditoria de ações e serviços prestados pelas unidades públicas e privadas credenciadas ao SUS;

- as responsabilidades e respectivas prerrogativas financeiras (modalidades de transferência de recursos federais e de remuneração de serviços) associadas a diferentes condições de gestão ${ }^{3}$ de estados e municípios;

- os requisitos específicos utilizados como base para avaliação da capacidade gestora das secretarias municipais e estaduais de saúde que pleiteiam a habilitação nas condições de gestão previstas, respectivamente, pelas Comissões Intergestores Bipartite (CIB) e Comissão Intergestores Tripartite (CIT). ${ }^{4}$

As características do processo de descentralização da política de saúde no Brasil - forte indução do nível central por meio de normas e estímulos financeiros; adesão baseada em critérios nacionais e condicionada à avaliação e decisão das instâncias de pactuação intergestores têm sido altamente questionadas. Entre as críticas apontadas destacam-se:

- as que ressaltam o caráter fortemente tutelado da descentralização pelo nível federal, que paulatinamente aumenta a vinculação dos recursos transferidos a determinadas políticas ou programas e diminui a autonomia de gestores estaduais e municipais de saúde na formulação de políticas próprias mais adequadas a sua realidade;

- as que discutem o efeito fragmentador desse processo, que ao privilegiar a descentralização para os municípios sem considerar adequadamente o papel das secretarias estaduais de saúde e as dificuldades para a montagem de um sistema integral na maioria dos municípios brasileiros, ${ }^{5}$ pouco contribuiu para a integração das redes municipais e garantia da assistência à saúde em todos os níveis de complexidade do sistema;

- as que se referem à inconstitucionalidade da regulamentação feita mediante portarias ministeriais que, por diversas vezes, colidem com os princípios previstos nas Leis da Saúde para alocação dos recursos federais e extrapolam o conteúdo normativo da alçada do poder executivo;

- as que enfatizam que o processo de transferência de responsabilidades e recursos do nível federal para os demais níveis de governo não garante per se o fortalecimento do caráter democrático do processo decisório na for- 
mulação de políticas, nem, necessariamente, possibilita a solidez das capacidades administrativas e institucionais dos governos locais, regionais e central. O fortalecimento institucional dos três níveis de governo dependem de alterações mais amplas do Estado - reformas tributárias e do próprio sistema político-administrativo - que transcendem o espaço da política setorial. Portanto, a concretização do SUS não está relacionada apenas à descentralização, mas também a outros aspectos relevantes para a consolidação do sistema.

Sem desconsiderar a importância desse debate, a segunda parte deste artigo pretende discutir os efeitos concretos do processo de descentralização da política de saúde no Brasil, particularmente, daqueles obtidos ao final da década de 90 e mais diretamente relacionados à implantação da NOB 01/96, sobre a redução das iniqüidades regionais nos campos da distribuição de recursos financeiros, nas oportunidades de acesso e na utilização de serviços. Parte-se do princípio de que, embora a descentralização no Brasil esteja associada à estratégia de democratização e incorporação de novos atores sociais, bem como à perspectiva de construção de sistema, seus benefícios só poderão ser percebidos à medida que contribuírem para a reversão do alto grau de exclusão, heterogeneidade e injustiça social da sociedade brasileira.

Para tanto, serão utilizadas algumas informações produzidas pela pesquisa Avaliação da Gestão Plena do Sistema Municipal, ${ }^{6}$ que compreende uma análise da gestão descentralizada do SUS a partir de 1998, com ênfase nos 523 municípios habilitados na Gestão Plena do Sistema Municipal (GPSM) na NOB 01/96 até o final de 2000. Primeiramente, serão apresentadas algumas características gerais dos municípios estudados. Em seguida, será analisada a distribuição de alguns indicadores de alocação dos recursos federais, oferta e cobertura, conforme as diferentes regiões e porte populacional no universo dos municípios habilitados em GPSM.

\section{Características Gerais dos Municípios Habilitados em GPSM}

Os municípios habilitados em GPSM até dezembro de 2000, embora formalmente iguais perante a NOB 01/96, do ponto de vista de suas responsabilidades e atribuições, são bastante desiguais quanto a suas condições socioeconômicas e demográficas, a suas capacidades fiscais, a sua trajetória no SUS e a suas disponibilidades de recursos de saúde (incluindo recursos financeiros, capaci- dade instalada e capacidade de produção de ações e serviços). Além disso, a gestão municipal plena dos recursos federais para custeio da assistência à saúde está condicionada pelos acertos e negociações definidos em nível estadual pelas respectivas instâncias intergestoras (CIB).

Feitas essas considerações, em síntese, os municípios em GPSM representam a condição de gestão mais avançada no sistema prevista pelas regras da descentralização na NOB 01/96. Representam apenas 9,5 do total de municípios brasileiros e são aqueles, portanto, com maiores responsabilidades gestoras e com prerrogativa de recebimento da totalidade dos recursos federais de custeio transferidos diretamente do Fundo Nacional de Saúde para os Fundos Municipais. Esses municípios têm autonomia administrativa e financeira dos recursos federais - para a programação, controle, avaliação e pagamento de prestadores de serviços públicos e privados localizados em seu território - que respondem, em média, no ano 2000, por cerca de $54 \%$ do total de gastos públicos em saúde realizados.

O processo de adesão desses municípios à habilitação em GPSM ocorreu, principalmente, em 1998 (86\% das habilitações) e, ao final de 2000, a maioria desses municípios localizava-se na região Sudeste (51\%), seguida da região Nordeste (25\%) e Norte do país (11\%).

Em relação ao tamanho, sua população, majoritariamente, gira em torno de 10 mil a 100 mil hab. (70,2\%), e os municípios podem ser considerados de pequeno e médio porte. Ressalta-se que os municípios com esse porte populacional albergam, atualmente, cerca de $40 \%$ da população brasileira.

\section{Redução das Iniqüiidades na Alocação dos Recursos Financeiros}

No que se refere à alocação dos recursos financeiros federais para custeio da assistência à saúde, observa-se, no período de 1998 a 2000, crescimento significativo do montante de recursos destinados a esses municípios: de $\mathrm{R} \$ 50,50$ para R\$ 70,50 per capita (Gráfico 1).

Embora os recursos sejam menores e permaneçam abaixo da média nacional na região Norte do país - muito em função dos critérios utilizados para definição do montante de recursos a serem transferidos, que privilegiam a capacidade de oferta e produção na média e alta complexidade -, observa-se maior incremento de recursos no período nesta região. Vale a pena destacar que os recursos transferidos para a região Nordeste superam os transferidos para a região Sudeste. 


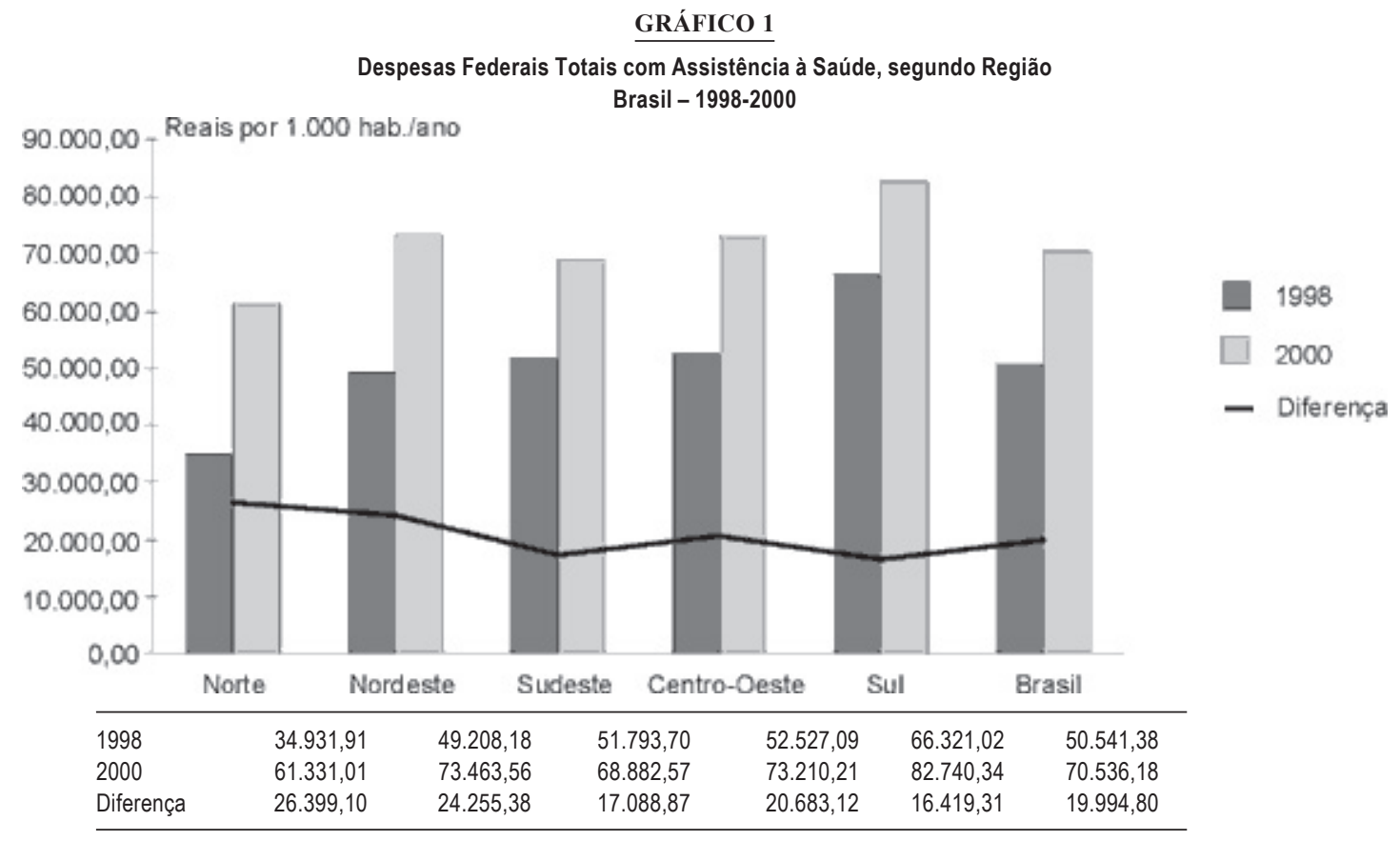

Fonte: Banco de dados da Pesquisa Avaliação da Gestão Plena do Sistema Municipal, 2002.

Nota: Municípios habilitados em GPSM até dez. de 2000.

GRÁFICO 2

Despesas Federais Totais com Assistência à Saúde, segundo Porte Populacional dos Municípios Brasil - 1998-2000

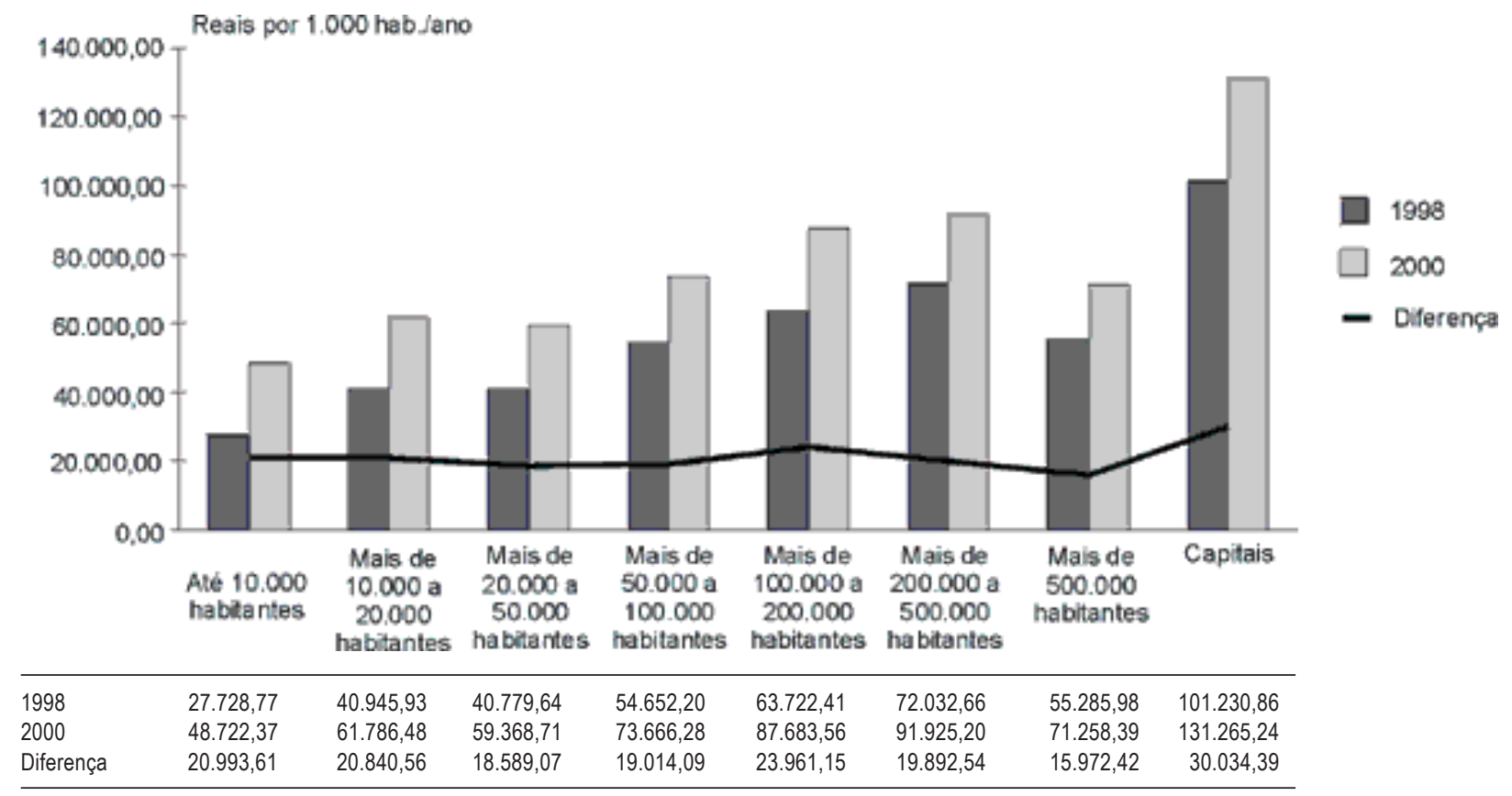

Fonte: Banco de dados da Pesquisa Avaliação da Gestão Plena do Sistema Municipal, 2002. Nota: Municípios habilitados em GPSM até dez. de 2000. 
GRÁFICO 3

Participação de Unidades Laboratoriais Públicas no Total de Unidades Ambulatoriais Cadastradas no SUS, segundo Região

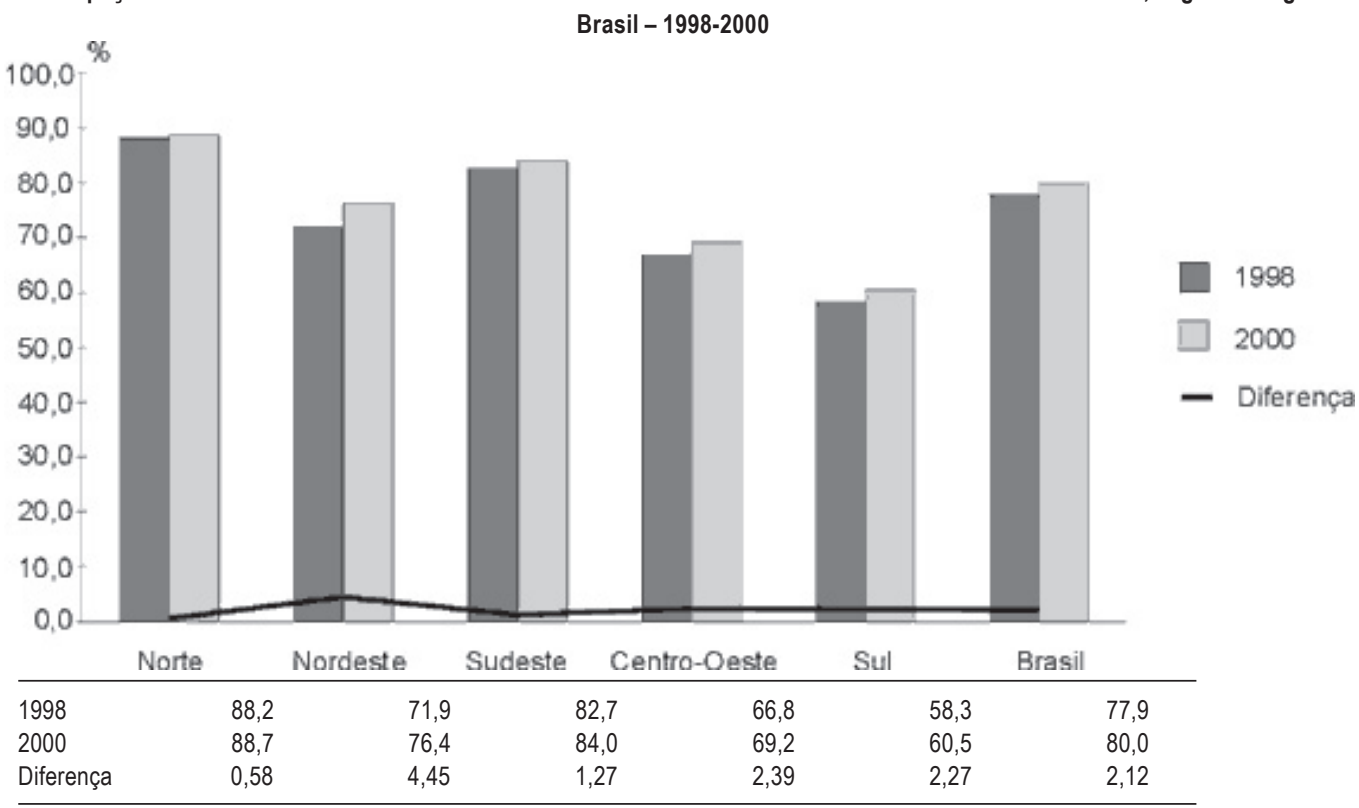

Fonte: Banco de dados da Pesquisa Avaliação da Gestão Plena do Sistema Municipal, 2002

Nota: Municípios habilitados em GPSM na NOB 01/96 até dez. de 2000.

\section{GRÁFICO 4}

Número de Leitos, segundo Região

Brasil - 1998-2000

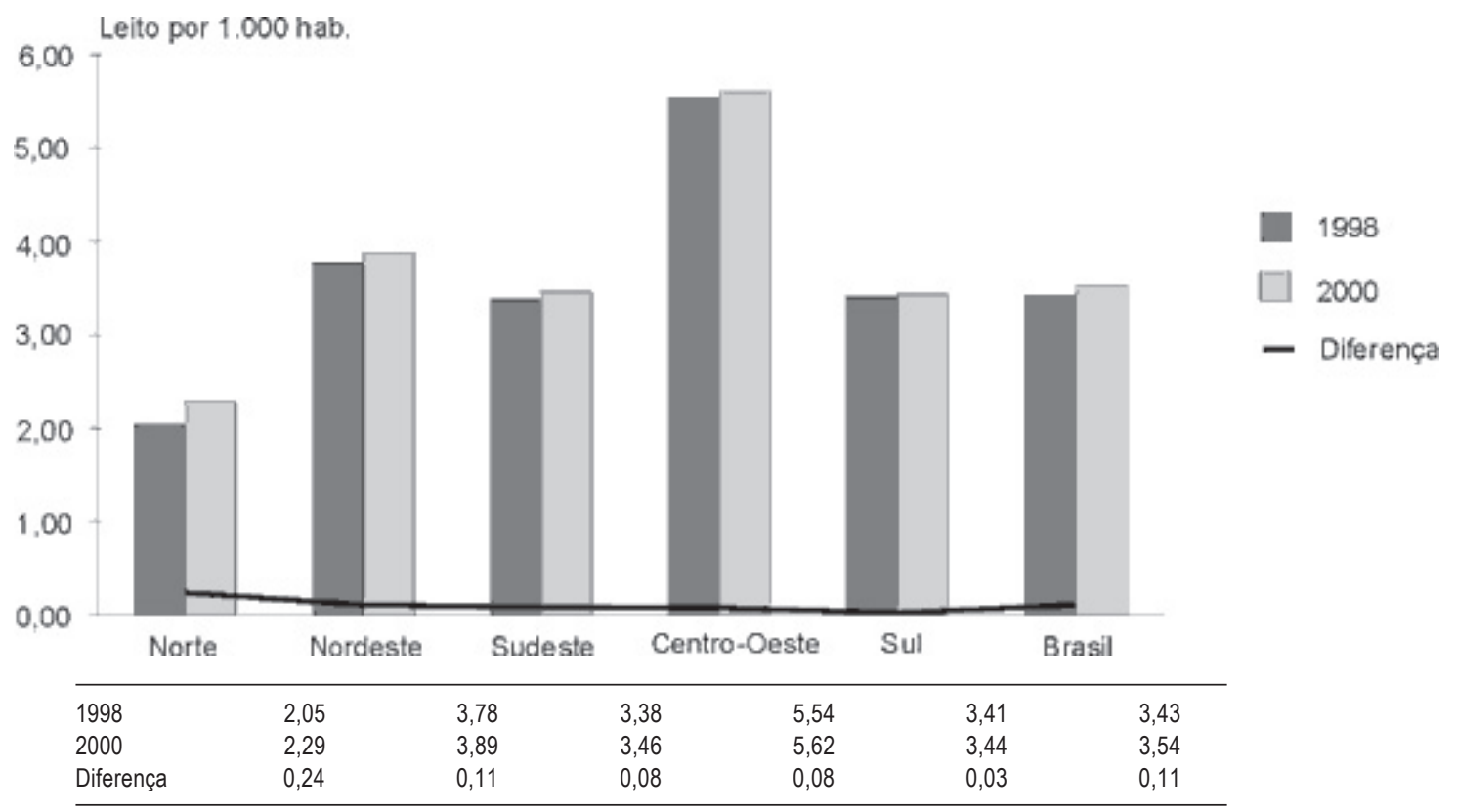

Fonte: Banco de dados da Pesquisa Avaliação da Gestão Plena do Sistema Municipal, 2002.

Nota: Municípios habilitados em GPSM na NOB 01/96 até dez. de 2000. 


\section{GRÁFICO 5}

Número de Consultas Médicas Totais, segundo Região Brasil - 1998-2000

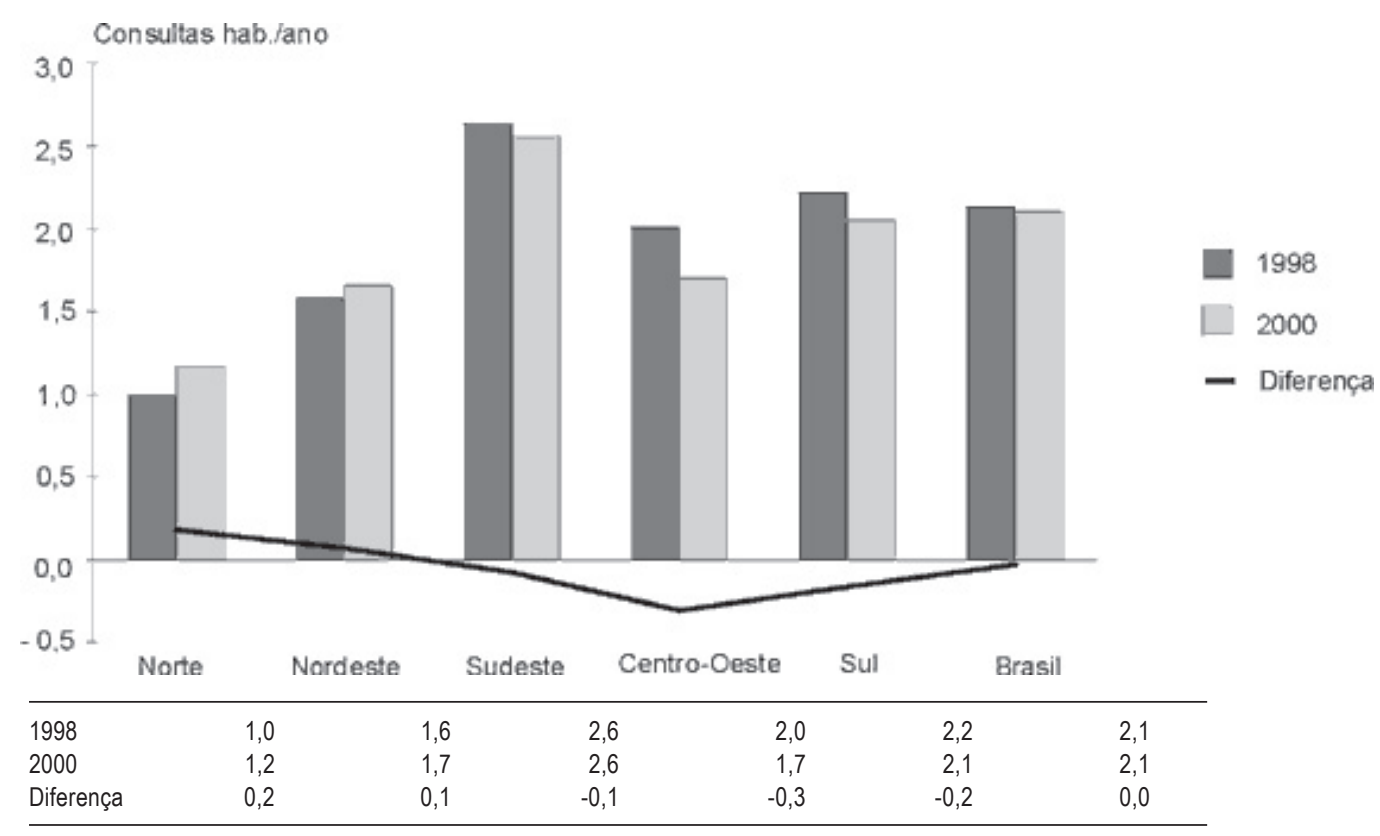

Fonte: Banco de dados da Pesquisa Avaliação da Gestão Plena do Sistema Municipal, 2002. Nota: Municípios habilitados em GPSM na NOB 01/96 até dez. de 2000.

GRÁFICO 6

Número de Exames Laboratoriais Totais, segundo Região Brasil - 1998-2000

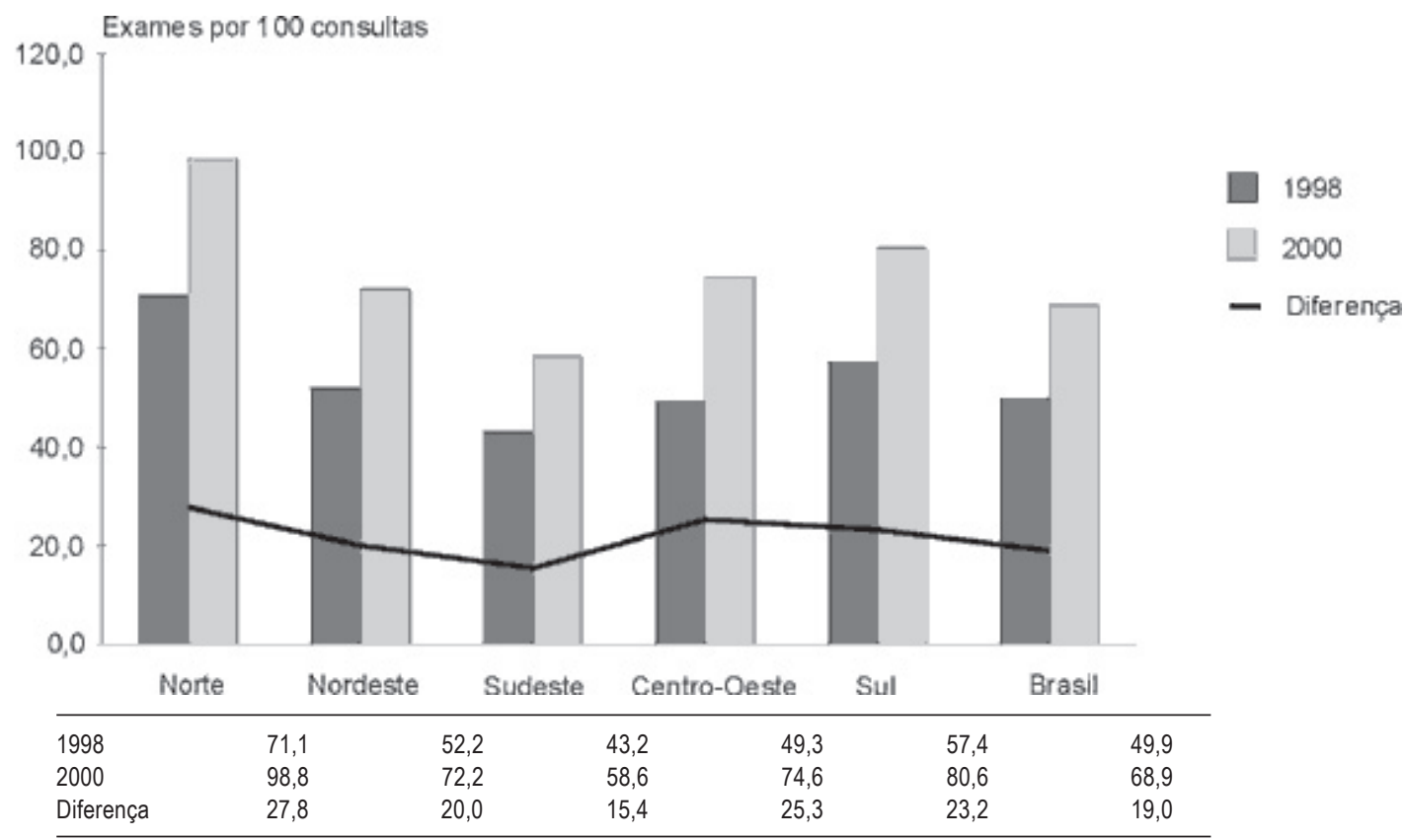

Fonte: Banco de dados da Pesquisa Avaliação da Gestão Plena do Sistema Municipal, 2002 Nota: Municipios habilitados em GPSM até dez. de 2000. 


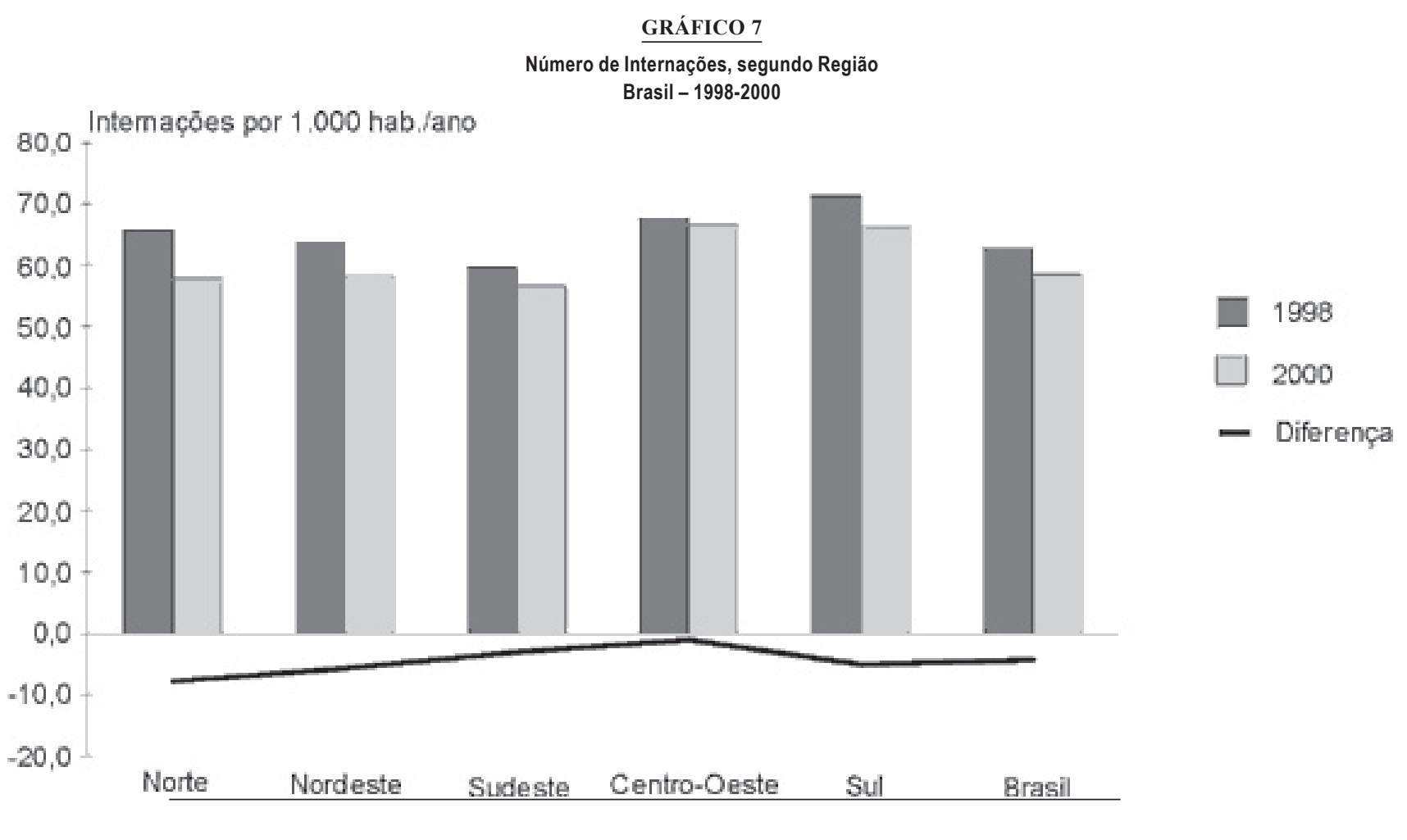

Fonte: Banco de dados da Pesquisa Avaliação da Gestão Plena do Sistema Municipal, 2002. Nota: Municipios habilitados em GPSM na NOB 01/96 até dez. de 2000.

Se se considerar, no entanto, a distribuição de recursos para os municípios em GPSM segundo porte populacional, pode-se perceber que as capitais e os municípios com 100 mil a 500 mil hab. foram privilegiados na alocação de recursos (Gráfico 2). É verdade que os pequenos municípios recebem importante incremento de recursos entre 1998 e 2000 , porém, são eles os mais dependentes dos recursos federais. Em 2000, as transferências para o SUS representam 36\% do gasto público total em saúde no grupo de municípios com população menor que 10 mil hab.

Resta salientar que o volume de recursos transferidos é ainda irrisório se se considerar o alto grau de dependência da fonte federal no gasto público total em saúde nesses municípios. Eles já alocam, em média, 15\% de sua receita própria em saúde cumprindo com o dispositivo da Emenda Constitucional 29, publicada em 2000. Mesmo assim, a dependência permanece, e é menor nas regiões Sudeste e Centro-Oeste do país.

\section{Redução das Iniqüidades na Oferta}

Pela oferta ou pela oportunidade de acesso, pode-se verificar um aumento insignificante no percentual de uni- dades ambulatoriais públicas no total de unidades cadastradas no SUS nos municípios em GPSM (Gráfico 3). Essas unidades, no entanto, já representam $80 \%$ do total de unidades cadastradas em 2000, e sua participação é maior nas regiões Norte $(88,7 \%)$ e Sudeste $(84 \%)$ do país. A preponderância da oferta pública na área ambulatorial é observada em todas as regiões do país, com destaque para os pequenos municípios - 94,5\% nos municípios com até 10 mil hab. e $86,8 \%$ nos municípios com população entre 10 mil e 20 mil hab.

A área hospitalar, por sua vez, apresenta padrão inferior ao preconizado pelo MS (4 leitos por mil hab.), se se considerar a média nacional $(3,54$ leitos por mil hab.) desses municípios (Gráfico 4). Esse padrão varia, significativamente, entre as regiões, apresentando os valores mais baixos no Norte (2,29 leitos por mil hab.) e mais elevados no Centro-Oeste (5,62 leitos por mil hab.).

$\mathrm{O}$ incremento verificado no período privilegiou a região Norte (região mais carente da oferta de leitos) e Nordeste (segunda região com maior oferta de leitos) e os municípios com menos de 10 mil hab. Os municípios com população maior do que $500 \mathrm{mil} \mathrm{hab.} \mathrm{que} \mathrm{não} \mathrm{são} \mathrm{capi-}$ 
tais, permanecem com um padrão bem inferior à média nacional (1,57 leitos por mil hab.) e que apresentaram decréscimo de leitos no período.

Destaca-se que a política nacional de investimentos (basicamente recursos originários do Banco Mundial no projeto Reforsus) não acompanhou as regras e as tendências da política de descentralização, isto é, os critérios utilizados para alocação dos recursos de investimentos obedeceram a regras diferentes das previstas na NOB 01/96 para a descentralização de competências gestoras. Esse descolamento representa um limite para expansão da alocação dos recursos de custeio nas regiões mais carentes.

\section{Redução nas Iniqüidades na Utilização de Serviços}

Em relação à utilização de serviços, a análise da distribuição de consultas médicas totais (básicas, especializadas e de urgência/emergência) por habitante/ano segundo regiões (Gráfico 5) e porte populacional dos municípios em GPSM aponta para a manutenção das diferenças regionais, redução do número de consultas nas capitais e manutenção de baixos valores de cobertura entre 1998 e 2000 , se se levar em consideração a média nacional (2,1 consultas por hab./ano). Ressalta-se que as regiões Sudestes e Sul mantêm os maiores coeficientes de cobertura (respectivamente, 2,6 e 2,1 consultas por hab./ano), assim como os municípios com menos de 10 mil hab. (2,8 consultas por hab./ano).

O padrão de cobertura é mantido graças ao significativo incremento da cobertura de consultas básicas no período (de 0,28 para 1,4 consultas por hab./ano), já que se observa, de outra parte, uma diminuição das consultas especializadas (de 0,63 para 0,3 consultas por hab./ano). Essa reversão - incremento de consultas básicas e decréscimo de consultas especializadas - pode ter ocorrido graças a mudanças no modelo de atenção à saúde com a implantação do Programa de Saúde da Família (PSF) nesses municípios. O número elevado de consultas básicas nos pequenos municípios e baixo nos municípios maiores, em que o PSF permanece residual, favorece tal hipótese.

Ainda no que diz respeito à cobertura de serviços ambulatoriais, destaca-se o expressivo aumento do número de exames por consulta que ultrapassa o parâmetro de $30 \%$ a 50\% das consultas preconizado pelo MS (Gráfico 6). Esse aumento que é bastante expressivo no Norte e nos municípios com mais de 500 mil hab. e capitais, pode também significar a ausência de rotinas e protocolos na organização da assistência médica, bem como a de controle e avaliação dos serviços realizados.
No que se refere a cobertura hospitalar, verifica-se uma regressão no número de internações por hab./ano no período (Gráfico 7). A média nacional nos municípios em GPSM (0,05 internações por hab./ano) permanece abaixo dos parâmetros recomendados pelo MS (0,08 a 0,09 internações por hab./ano) em todas as regiões. Embora com padrão semelhante entre as regiões, as coberturas mais baixas encontram-se nas regiões Sudeste e Nordeste, enquanto o maior decréscimo pode ser observado no Norte. Em relação ao porte, destacam-se as maiores coberturas hospitalares nas capitais (0,07 internações por hab./ano) e nos municípios médios com 20 mil a 100 mil hab. (0,06 internações por hab./ano).

\section{CONCLUSÃO}

Cabe assinalar que os efeitos sobre eqüidade foram analisados para um universo particular de municípios brasileiros, por uma razão bem simples: só se pode comparar municípios com o mesmo tipo de inserção na política de saúde, isto é, com o mesmo status, quando se quer examinar a redução nos padrões anteriores de desigualdade no tocante à distribuição dos recursos e das oportunidades de acesso e utilização.

Municípios com status diversos na política de saúde proporcionado pelas diferentes modalidades de habilitações -, possivelmente apresentam diversidades provocadas por essa mesma diferenciação inicial: isto é bastante claro no tocante a distribuição e utilização dos recursos pelas instâncias municipais.

Os dados referentes aos anos de 1998 e 2000 evidenciam que houve alguns avanços quanto à eqüidade, sobretudo em relação à distribuição de recursos, o que é explicável: as reduções das desigualdades no acesso e na utilização são posteriores no tempo, isto é, dependem, em um primeiro momento, da melhor distribuição de recursos, que permite mais à frente investimentos novos e faculta, portanto, a maior utilização dos equipamentos e serviços de saúde.

Todavia, é notável como os indicadores nacionais, mesmo para esse grupo seleto de municípios, são bastante inferiores aos padrões de oferta e uso recomendados pelos organismos internacionais.

As reduções das iniqüidades quanto à alocação de recursos financeiros, oferta e utilização de serviços ainda necessitam de políticas pontuais que privilegiem determinados tipos de investimentos que melhor relacionem oferta às necessidades de saúde, diferentes condições de adoecimento e agravo e, ao mesmo tempo, melhorem o 
acesso e a utilização. As políticas recentes minoraram as graves distorções regionais na oferta, porém não contemplaram ainda questões mais complexas como o perfil epidemiológico das populações, condições sociais, diferentes inserções no mundo do trabalho, gênero e raça. $\mathrm{O}$ processo de implementação do SUS, no país, deve ainda percorrer um longo caminho para diminuição das iniqüidades na saúde, e possibilitar, desse modo, a diminuição das desigualdades sociais. Para isso, deve, cada vez mais, diversificar políticas e ações segundo grupos específicos de indivíduos.

\section{NOTAS}

1. “... Para o ano 2000, as atuais diferenças nas condições de saúde entre países e entre grupos dentro de países, seriam reduzidas, em pelo menos $25 \%$, melhorando tanto o nível de saúde das nações, quanto os grupos em desvantagem". (Tradução dos autores). Targets for health for all. Copenhagen, WHO Regional Office for Europe, 1985.

2. Nos anos 90, foram publicadas quatro dessas normas: as Normas Operacionais Básicas (NOB) de 1991, 1992 (similar à anterior), 1993 e 1996. Mais recentemente, foi publicada a Norma Operacional da Assistência à Saúde (Noas) nas versões 2001 e 2002.

3. As diversas condições de gestão do SUS foram primeiramente estabelecidas pela NOB 01/1993 e referem-se a diferentes capacidades de gestão das secretarias municipais e estaduais de saúde, que envolvem determinado conjunto de exigências e prerrogativas financeiras. Em última instância, como as normas definem os mecanismos e os critérios de transferência dos recursos federais para custeio da assistência, as condições de gestão estão relacionadas a diferentes graus de autonomia de gestão apenas desses recursos financeiros, utilizados para remuneração das ações e dos serviços prestados no campo de ação do SUS.

4. O modelo institucional proposto no SUS prevê a criação de instâncias de negociação e decisão intergestores: as CIB, atuantes no nível estadual desde 1993, de composição paritária, formadas por representantes das secretarias estaduais de saúde e das secretarias municipais de saúde indicados pelo Conselho dos Secretários Municipais de Saúde no estado (Cosems); a CIT, atuante no nível nacional desde 1991, também paritária, formada por representantes do Ministério da Saúde, das secretarias estaduais de saúde indicados pelo Conselho Nacional dos Secretários Estaduais de Saúde (Conass) e das secretarias municipais de saúde indicados pelo Conselho Nacional dos Secretários Municipais de Saúde (Conasem).
5. Destaca-se que, embora $51 \%$ da população brasileira atualmente resida em municípios com mais de 100 mil hab., a maior parte dos municípios são pequenos. Destes, $48 \%$ possuem população até $10 \mathrm{mil}$ hab. e $30 \%$ população entre 10 mil e 25 mil hab., segundo dados do último censo realizado pela Fundação IBGE.

6. A pesquisa, financiada pelo Banco Mundial, no âmbito do projeto Reforsus, foi realizada por um grupo de pesquisadores vinculados a diferentes instituições de ensino e pesquisa. Os dados da pesquisa estão disponíveis em CD-ROM e foram recentemente publicados por Negri e Viana (2003).

\section{REFERÊNCIAS BIBLIOGRÁFICAS}

MACINKO, J.A.; STARFIELD, B. Annotated bibliography on equity in health. International Journal for Equity in Health, Baltimore, v.1, n.1, 2002. Disponível em:

$<$ http://www.equityhealth/healthj.com/content/1/1/1>.

MACKENBACH, J.P.; KUNST, A. E Measuring the magnitude of socio-economic inequalities in health: an overview of available measures illustrated with two examples from Europe. Social Science and Medicine, Inglaterra, v.44, n.6, p.757-771, 1997.

NEGRI, B.; VIANA, A.L.d' (Orgs.). O SUS em dez anos de desafio. São Paulo: Sobravime/Cealag., 2003.

RAWS, J. Uma teoria da justiça. Tradução de Almiro Pisetta e Lenita M. R. Esteves. São Paulo: Martins Fontes, 2000.

SEN, A. Desigualdade reexaminada. Tradução de Ricardo Doninelli Mendes. São Paulo: Record, 2001.

STARFIELD, B. Improving equity in health: a research agenda. International Journal of Health Services. Inglaterra: v.13, n.3, p. 545-566, 2001.

TRAVASSOS, C. Eqüidade e o sistema único de saúde: uma contribuição para debate. Cadernos de Saúde Pública. Rio de Janeiro, v.13, n.2, p.325-330, abr./jun. 1997.

WHITEHEAD, M. The concepts and principles of equity and health. Copenhague: World Health Organization, 1991.

Ana Luiza d’Ávila Viana: Economista, Professora do Departamento de Medicina Preventiva da Faculdade de Medicina da USP.

Márcia Cristina Rodrigues Fausto: Assistente social da Fiocruz.

Luciana Dias de Lima: Assistente de pesquisa da Fiocruz. 